Martín S. Stabb. Jorge Luis Borges. New York: Twayne Publishers, Inc., 1970.

Entre tanto trabajo especializado -en un aspecto o un género de la obra de Borges - o, lo que es peor, partidista (a favor o en contra de Borges), el libro del profesor Stabb viene a llenar una necesidad durante largo tiempo sentida entre los estudios dedicados al lúcido escritor agentino. Stabb se ha propuesto, y lo ha logrado - de acuerdo con las normas editoriales de la colección de autores mundiales Twayne- un examen objetivo y completo de la figura y la obra de Borges, abarcando la biografía y el estudio de la producción del autor en cada uno de los géneros cultivados por él. Precedido por una cronología, el libro consta de cinca capítulos, titulados, en el orden en que aparecen: "Borges: The Man and His Time", "Borges the Poet", "Borges the Essayist", "Borges the Writer of Fiction" y "Borges and the Critics".

Particularmente importante para los estudiosos de la obra de Borges es el último capítulo, donde Stabb presenta y discute, con penetración y gracia, y sin faltar por ello al precepto de objetividad que le guía, las distintas actitudes de los críticos -argentinos e internacionales- frente a dicha obra. Más que una bibliografía crítica, es un cuidado ensayo de "situación" de la literatura de Borges de acuerdo con distintos ámbitos, contextos, posiciones.

E1 libro de Stabb es, no sólo un trabajo serio de "divulgación" sobre la obra total de Borges aparecido en inglés, sino que ha de ser libro imprescindible para el estudiante y el crítico (no necesatiamente de habla inglesa) que desee orientarse al emprender la lectura o el estudio del autor argentino.

\title{
Pennsylvania State University at
} N.s'w Kensington

\section{Luis F. González Cruz}

THOMAS A. SEBEOK, ed. Current Trends in Linguistics IV: Ibero-American and Caribbean Linguistics. The Hague [and] Paris: Mouton, 1968.

Este volumen es la recopilación de una serie de panoramas o vistas históricamente orientadas que se proponen examinar las corrientes lingüísticas contemporáneas en Iberoamérica. El grueso tomo (xix + 659p.) consta de cuatro partes: I: General and Ibero-American Linguistics, II: Linguistics of NonIbero-American Languages, III: Applied Linguistics, IV. Sources and Resources, subdivididas en veinticuatro capítulos, cada uno de distinto autor. Cuarto tomo de una serie realizada bajo el patrocinio de la United States Office of Education, ha salido impreso con esmero, y constituye un repertorio documental y críitco de gran utilidad para lingüistas de cualquier especialización y para todo hispanista.

La parte correspondiente a las lenguas indígenas abarca las lenguas clásicas precolombinas así como las modernas, y les interesará más a los lingüistas del indigenismo y a los antropólogos. En cambio, todo profesor, sea secundario o universitario, podrá seguir fácilmente la exposición, de fácil lectura, sobre la 
lingüística aplicada; trata, entre otros temas, del alfabetismo, del bilingüismo, y de la enseñanza de idiomas. De escasa documentación (exceptúese la contribución de Guitarte-Torres Quintero, que consideratemos más adelante) no alcanza el nivel erudito que es característico de los otros trabajos de esta serie; son más bien ensayos de divulgación, por lo general poco profundos. De mayor interés para los investigadores hispanistas es la primera parte, tanto por sus temas cuanto por su encuadre erudito.

Erica García apunta lo esencial sobre "Hispanic Phonology" en una ojeada rápida (17 páginas), pero la bibliografía, que agrega al final del trabajo, sirve para guiar al lector hacia estudios más pormenorizados. El breve panorama no ha podido conocer el estudio más reciente, hecho por James W. Harris, Spanish Pbonology (Cambridge, Mass.: MIT Press, 1969), donde se analizan algunos intricados problemas según los métodos de la fonología generativa, difundida por Chomsky, Halle, y otros de Ia llamada "Escuela MIT". El resumen de García, pues, no va más allá del enfoque fonológico iniciado en Hispanoamérica con trabajos tentativos de Amado Alonso y Tomás Navarro, y continuado de vez en cuando por investigadores como A. Zamora Vicente y G. Guitarte en sus estudios sobre peculiaridades fonológicas del dialecto porteño. De modo que, a los tres años de publicarse, este capítulo ya está algo anticuado.

Breve y deliberadamente esquemática es la contribución "Lexicography" por Fernando Antonio Martínez. Tras una enumeración de los principales diccionarios, pasa a una discusión de los fundamentos teóricos de la lexicología moderna, principalmente los que habia asentado Uriel Weinteich en otro tomo (III) de esta serie.

Lo fundamental de esta primera parte se halla en cuatro estudios por especializados lingüistas, todos de gran renombre. Sus perspectivas críticas, tan distintas y hasta opuestas entre sí, le dan a estos estudios doble valor: la información que reúnen y los comentarios valorativos, siempre personales y hasta polémicos.

Eugenio Coseriu inicia esta sección con un estudio de conjunto "General Perspectives". Breve historia de las investigaciones lingüísticas realizadas en las universidades iberoamericanas, refiere también la vida azarosa de sus principales revistas, de las cuales no pocas han muerto bajo el vendeval de trastornos políticos. Un obstáculo difícil de superar ha sido la falta de importantes revistas norteamericanas y europeas en las bibliotecas de estos centros. Según Coseriu, la lingüística moderna llegó a Sudamérica en forma del idealismo vossleriano, ingrediente esencial de la obra de A. Alonso y de sus discípulos en Buenos Aires. Actualmente viene siendo la dialectología el campo de más fructífero cultivo. Coseriu admite la evidente pobreza en cuanto a contribuciones originales sobre la lingüistica teórica, no exceptuando más que su propia labor realizada en Montevideo. Aunque suene a autoelogio, Coseriu tiene razón al considerarse a sí mismo la figura hispanoameticana cuya obra tiene más transcendencia universal. (p. 59).

Es poco conocida en Norteamérica y Europa la contribución de los demás lingüistas; posiblemente Coseriu ha hecho caso omiso de B. Terracini, lo cual no desmiente por completo $l_{a}$ validez de esta situación lamentable. A. Alonso había creado un vínculo, hoy gravemente aflojado, entre Hispanoamérica y Europa, y sigue siendo el lingüista mejor conocido en el extranjero, aunque 
tampoco reverbera el eco de su voz fuera de las aulas de filología románica e hispánica. La desmembración del Instituto porteño a partir de 1946 ha colocado la lingüística sudamericana en nueva época de aislamiento científico.

Juan M. Lope Blanch dedica unas cincuenta páginas a "Hispanic Dialectology". Resume la polémica sobre el supuesto andalucismo del español de América, tesis rechazada por P. Henríquez Ureña, pero ahora fuertemente reanimada por un trabajo tardío pero sumamente brillante de R. Menéndez Pidal, ${ }^{3}$ así como por las investigaciones histórico-biográficas, todavía en preparación, de P. Boyd-Bowman. Por otra parte, el autor cree que las encuestas dialectales no han salido de su infancia: la de T. Navarro, El español de Puerto Rico (Río Piedras, 1948), queda como la más completa y meritoria. Lope Blanch lo califica "not only a careful description of the present state of Spanish in this Carribean island but is also an excellent methodological approach as to how the main questions of dialectal geography should be treated." (p. 111). Este juicio es sumamente des. concertante, puesto que Navarro hizo sus encuestas en los años 1927-28, publicando los resultados a raíz de su traslado permanente al Nuevo Mundo. ¿No ha evolucionado la lengua puertorriqueña en cuarenta años, ni la metodología ha adelantado en las dos últimas décadas? Al final, Lope Blanch pide que se hagan estudios en los grandes centros urbanos, focos de irradiación cultural y lingüística, en vez de llevarlas a cabo en las comarcas rurales, como lo han pteferido Navarro y la mayoría de sus discípulos. También anhela mejor coordinación de los diversos proyectos individuales.

El estudio de Yakov Malkiel, "Hispanic Philology", abarca los más diversos campos, entre lingǘstica y literatura, que vienen siendo cultivados por los seguidores de Menéndez Pidal. El autor comienza por advertir que la aportación latinoamericana en esta materia ha sido "modest", y luego traza detenidamente los logros y fracasos de estos estudios en Hispanoamérica y sus ramificaciones en Norteamérica y en Europa. Dotada de una documentación asombrosamente copiosa y minuciosa, rasgo distintivo de toda la obra de Malkiel, la reseña es la más erudita y completa de este tomo. Sin embargo, muchos de sus juicios son discutibles y son contrariados en otras contribuciones del volumen. Aun reconociendo los méritos de la obra de A. Alonso, siempre le halla defectos o lagunas (p. 167-68). Elogia sin reserva la prodigiosa producción de María Rosa Lida de Malkiel (p. 212-14), pero critica severamente los trabajos de Ángel Rosenblat, a quien le reprocha la falta de tono erudito (p. 206.08) y de tigor científico (p. 168-69). Pero en la contribución de Coseriu leemos que el profesor Rosenblat es la figura máxima de la lingüistica hispanoamericana, el mejor conocedor del español de América y de la historia de la lengua. (p. 18n). Tales contradicciones se deben, sin duda, a las distintas orientaciones de dichos colaboradores. Como se ve, el tomo que reseñamos carece de un criterio uniforme, Io cual no implica una crítica de nuestra parte, y estamos seguros de que servirá de estímulo a futuras investigaciones y críticas sobre la filología hispanoamericana.

El reciẹ́n fallecido J. Mattoso Câmara Jr. lamenta el estado rezagado de

1 "Sevilla frente" a Madrid: Algunas precisiones sobre el español de América," Estructuralismo e bistoria (Homenaje a Martinet): [La Laguna, 1962], III, 99-165. 
los estudios luso-brasileños en la parte "Brazilian Linguistics". Todavía se echa de menos la presencia de Serafim Silva Neto, investigador del latín vulgar y de 1a historia del portugués. Silva Neto fue el único brasileño (a no ser el otro el mismo Mattoso Câmara) cuya obra alcanzó niveles de solvencia internacional. En su vistazo breve y pesimista, el autor concluye que en Brasil los estudios linguísticos están todavía por hacer. Ahora podemos agregar que la pérdida inesperada de Mattoso Câmara augura algo peor para el futuro inmediato.

En la cuarta parte se destaca la contribución "Linguistic Correctness and the Role of the Academies", por Guillermo L. Guitarte y Rafael Torres Quintero. A veces deteriora la ponencia una traducción inglesa malograda (p. ej. p. 565 passim). Basados en una nutrida bibiografía, los autores historian el desarrollo de las Academias de la Lengua en Iberoamérica. En cuanto a la gramática normativa, la doctrina de Bello y Cuervo todavia está en pleno vigor: hasta la Real Academia Española reconoce su deuda al filólogo venezolano en sucesivas ediciones de su universalmente consagrada Gramática. Sarmiento intentó imponer una ortografía distintivamente hispanoamericana, esfuerzo que no fue abandonado oficialmente en Chile hasta 1927; ahora las Nuevas Normas (1952 y 1959) de la R.A.E. han triunfado en todas partes. La cooperación lingüística entre los países hispánicos está hoy facilitada por los Congresos de Academias que se han venido reuniendo cada cuatro años desde 1951. Por eso, los autores son optimistas en cuanto al porvenir de la unidad lingüistica hispánica; no temen ninguna desgarradora fragmentación, sino que prevén una más rápida y segura nivelación de las actuales divergencias.

Desde luego, en los límites de esta reseña no pretendemos considerar todos los estudios del volumen, pero no podemos dejar de reconocer el valor permanente de los datos bio-bibliográficos e históricos, si no los críticos, que se hallan reunidos aquí. Un índice de lenguas y dialectos y otro de nombres proporcionan al volumen una utilidad práctica, tanto para investigaciones de índole cultural, como para las puramente lingüísticas. Desigual en mérito, por ser trabajo no de equipo, sino de lingüistas independientes y hasta de varia y peculiar idiosincrasia, no obstante, este corpus ha de considerarse una ōbra de consulta imprescindible.

University of Pittsburgh

\section{Steven Hess}

Miguel Cossio Woodward. Sacchario. La Habana: Casa de las Américas, 1970

Según el crítico cubano Ambrosio Fornet, "es difícil escribir novelas sobre una sociedad con la que se está de acuerdo" (Casa de las Américas, 64, enerofebrero, 1971, p. 183). De ahi se deriva el valor casi ejemplar de la novela Sacchario, premiada en 1970 por la Casa de las Américas: "ejemplar" en el sentido de lo que debiera ser una novela dentro de un régimen socialista.

A pesar de que dos de los tres elementos estructurales de la novela están directamente relacionados con la caña de azúcar, el propósito principal es trazar no sólo la epopeya de la caña sino toda la génesis revolucionaria a través de 